Proceedings of the Seminar on the Social and Economic Effects

of Earthquake Prediction, 12 October, 1977.

\title{
SUMMARY OF EVENING DISCUSSION
}

Professor Roberts opened the evening discussion. He thought the central problem was the estimation of the reliability of oredictions. But it is not possible to estimate the reliability of predictions unless predictions are made. In the future there will therefore be predictions which have little or no reliability. Who was going to certify these predictions and issue official warnings, and dispense information?

How to handle the first prediction was really the only issue, for the experience would dramatically alter the character of actions taken following subsequent predictions. Professor Roberts opinioned that despite the day's discussions, the problem remained unsolved. He wondered how government departments would act, and whether civil liberties would be threatened.

Professor Roberts suggested that the social consequences of an earthquake prediction had been underestimated in the seminar. The event, afterall, would be front page rews for several days and he wondered what would happen to the fabric of society as it wound down to a disaster. Turning to the economic issues, he thought there were two main problems: how were the costs of mitigating the prediction to be fairly allocated within society, and how much should be spent anyway. He thought it would be easy to spend too much (especially for the first predictions of unknown reliability) and that there were plenty of other areas where society faced danger and economic loss and where the money might be better invested.

The final issue was what should be done now. Should regulations be devised and put in cold storage, and detailed responses devised so that action can be quickly taken at the time.

Open discussion followed. The seismologists were asked to say more precisely what earthquake prediction programmes were in operation in New Zealand, and whether the D.S.I.R. were actually in a position to issue a prediction.

In reply, Dr. Adams, Superintendent of the Seismological observatory, said that it should firstly be realised that nowhere in the world was a routine prediction service in operation. For example, although the Chinese scientists have come closer to success than most, they would not guarantee to predict every large earthquake, nor do they have a comprehensive prediction scheme working. He emphasised that there was a variety of precursors to observe and to compare, and in New Zealand efforts were still primarily directed toward recording background data against which apparent future changes could be compared. Professor Evison added that the topic was really predicting large earthquakes, and these occurred infrequently in New Zealand.

Mr. Lewis from the insurance industry pointed out that the New Zealand private insurance sector was controlled from overseas; either as branch operations of multi-national insurers or by international reinsurance who each year apply a 90 day cancellation clause as they assess their trading position. He wondered how a positive earthquake prediction would influence these decisions. (For example, the possibility of war normally gives rise to a cancellation of marine clauses on war. He suggested that legislative control over the cancellation of earthquake insurance might be worth considering. Mr. Hellburg of the Earthquake and War Damage Commission pointed out that most earthquake insurance in New Zealand was held by the Commission, and that therefore direct action in New zealand on this question may not be necessary.

There was further discussion of the role of Civil Defence in planning for a predicted earthquake. General Holloway reminded the seminar that as presently conceived Civil Defence was basically an extension of existing emergency services, and had very few permanent staff. There was no way that Civil Defence could at present become involved in detailed long term disaster response planning.

In summing up the seminar, Professor Roberts once again accused the participants of not grasping the effect of a prediction on a community once it is promulgated "....... it could actually destroy a cormunity. Government would be involved in a massive way immediately. As soon as discussion started, every trade organisation, industry and local government would be there with their hands out for the money, and every second individual would be wanting his bit to keep his property value up. Most of you have talked about events with lead times of say 3 months, with panic in the streets: but if you are talking about years then surely there will be no panic, but there certainly will be greed....... What will happen to the investment programmes, the $30 \%$ who want to leave the city, ...... and the mothers ...."

Professor Roberts suggested the best thing to do now was to imagine the prediction had been placed in the hands of the Minister and then to explore possibilities. clearly the Minister would first need high level technical vetting of the prediction. Secondly he must promulgate the prediction, for the consequences of not are too great (to the politician), when the scientists become publicly concerned. In the short term, Professor Roberts wanted more research on the possible social and economic effects of predictions, with plenty of public discussions. 
Let it be known that Ministers were considering the possibilities, insurance companies were investigating possible reactions and that businesses were seeking advice.

Finally, Frofessor Roberts charged the Society with the responsibility for disseminating the proceedings of the seminar widely, of promoting further discussion and research and of communicating effectively with the highest levels of government on the issue. 